\title{
A IMPORTÂNCIA DE APRENDER E ENSINAR COM EMOÇÃO
}

\author{
Maiara Evelyn Ebertz ${ }^{1}$
}

RESUMO: Os princípios de um espaço de aprendizagem voltado à construção integral dos sujeitos é tema relevante para pesquisas na academia. No momento atual, em que estamos todos atentos às mudanças que tem cerceado o cenário da educação; tratar sobre as relações entre os atores sociais na escola nos faz refletir sobre o fortalecimento desses vínculos a fim de providenciar uma educação de qualidade. Desta forma destacamos as leituras realizadas em que temos como principal suporte Gadotti (2003) do qual destacamos como evidência para este estudo entender como as emoções podem influenciar na educação das pessoas, e não somente na educação, mas também influencia no ensino. Percebesse que o professor deve levar em consideração o meio em que os alunos vivem, o que eles pensam, o seu contexto, professores nunca param de aprender. No que relacionamos com a pesquisa de cunho qualitativo a partir da análise de imagens o cenário real frente à pandemia, sendo nossas aprendizagens centradas nos seguintes resultados: temos necessidade em aprender, nascemos sem saber nada, mas ao longo da vida vamos aprendendo. Aprendemos com o contexto em que vivemos, o professor não pode deixar de perceber isso. Só aprendemos quando colocamos emoção no que aprendemos. O professor também precisa ensinar com alegria, viver a profissão feliz, para estar motivado deve estar realizado. A escola e os professores devem estar a tentos as mudanças na sociedade. Existem diversas dificuldades no campo educacional, mas os educadores devem lutar para superá-las. Devemos dar importância as emoções.

Palavras-chave: Emoções. Professor. Ensino. Aprendizagem.

ABSTRACT: The principles of a learning space aimed at the integral construction of subjects is a relevant topic for research in academia. At the present time, when we are all aware of the changes that have limited the education scenario; dealing with the relationships between social actors at school makes us reflect on the strengthening of these bonds in order to provide quality education. Thus, we highlight the readings carried out in which we have Gadotti (2003) as the main support, which we highlight as evidence for this study to understand how emotions can influence people's education, and not only in education, but also in education. Realize that the teacher must take into account the environment in which students live, what they think, their context, teachers never stop learning. In terms of qualitative research, based on image analysis, the real scenario in front of the pandemic, with our learning centered on the following results: we need to

\footnotetext{
${ }^{1}$ Graduanda em Pedagogia. Uniasselvi de Santo Antônio da Patrulha. E-mail: maiaraebertz@gmail.com.
} 
learn, we are born without knowing anything, but throughout life we learn. We learn from the context in which we live, the teacher cannot fail to notice this. We only learn when we put emotion into what we learn. The teacher also needs to teach with joy, live the profession happy, to be motivated, he must be fulfilled. The school and teachers must be aware of changes in society. There are several difficulties in the educational field, but educators must fight to overcome them. We must give importance to emotions.

Keywords: Emotions. Teacher. Teaching. Learning.

\section{INTRODUÇÃO}

Os princípios de um espaço de aprendizagem voltado à construção integral dos sujeitos no contexto escolar é o tema central deste trabalho, no que integramos ao mesmo as questões vivenciadas no momento atual em que o mundo é assolado pela pandemia do Covid-I9. Ressaltamos com isso nossa preocupação enquanto acadêmicos do curso a partir da análise de contextos próximos com suporte de imagens e uso dos escritos de Gadotti (2003) em um texto que ainda é atual e agudo sobre a realidade da educação brasileira.

Nesse contexto o trabalho está dividido em três capítulos nos quais temos o

conjunto de fundamentações teóricas eleitas para embasar o estudo, os materiais e métodos em que apresentamos nossas imagens de referência que tratam de mostrar de forma visual como a emoção é importante para o processo de ensino, uma criança feliz aprende melhor e um professor realizado ensina melhor. Outro ponto levantado nas imagens é problematizar como será a volta as aulas depois da pandemia em que vivemos hoje. Muitos vão ser os processos de volta, também haverá muito cuidado, o uso de máscara, manter o distanciamento seguro, vai demorar para tudo voltar ao normal.

No capítulo de Resultados e Discussões trazemos a relação da teoria e da prática em que temos um percurso analítico que expressa nossas principais reflexões sobre aprender com emoção e ensinar com alegria, o professor como pesquisador deve estar sempre atento as mudanças na sociedade em que vivemos, no contexto dos seus alunos. Aprender não é um habito, mas sim uma necessidade do ser humano, precisamos aprender para sobreviver. No momento em que o professor se forma deve entender que sua maior preocupação é em ensinar da melhor forma possível, vamos ver nos textos abaixo que as emoções influenciam no ensino-aprendizado dos alunos, os educadores também precisam estar 
satisfeitos com seu papel na escola. É obvio que, não é fácil, tudo depende de muito aprimoramento, mas o professor deve dar o seu melhor. Sendo por fim apresentada na conclusão a expressão sobre os resultados da pesquisa e prospecções futuras sobre o tema em nossa formação.

\section{DESENVOLVIMENTO}

A todo momento estamos aprendendo coisas novas, pois podemos aprender assistindo, ouvindo, ensinando, dialogando. $\mathrm{O}$ ser humano tem uma capacidade imensa de capturar várias informações e de lembrar delas, claro uns mais que outros. A criança nasce sem saber de praticamente nada, mas ao longo da vida vai adquirindo conhecimentos, desde as primeiras palavras.

A habilidade de aprender e ensinar é um dos motivos que nos fez sobreviver até hoje, a humanidade passou por diversos processos evolutivos, o que fez que cada um dos nossos antepassados aprendesse coisas diferentes, hoje não teríamos tanto conhecimento se as pessoas antigamente não tivessem repassado para os demais. Estamos em constante aprendizado, é visível que a "educação é necessária para a sobrevivência do ser humano" (GADOTTI, 2003, p. 59).

Um bom professor deve estar ciente do contexto dos alunos, cada aluno vem de uma comunidade, onde todos têm sua história, suas crenças, seu poder econômico. Por exemplo, podemos ver diferenças entre escolas católicas e escolas normais, cada uma tem suas particularidades. Nunca paramos de aprender, estamos em constante aprendizado, ter autonomia no ensino é importante para a construção do conhecimento. O educador deve aprender a todo momento.

Todo ser vivo aprende na interação com o seu contexto: aprendizagem é relação com o contexto. Quem dá significado ao que aprendemos é o contexto. Por isso, para o educador ensinar com qualidade, ele precisa dominar, além do texto, o "com-texto"; além de um conteúdo, o significado do conteúdo que é dado pelo contexto social, político, econômico, histórico... do que ensina. Nesse sentido, todo educador é também um historiador.

Nós, educadores, precisamos ter clareza do que é aprender, do que é "aprender a aprender", para entendermos melhor o ato de ensinar. Não basta saber como se constrói o conhecimento. Nós precisamos dominar outros saberes da nossa difícil 
tarefa de ensinar. Precisamos saber o que é ensinar, o que é aprender e, sobretudo, como aprender. (GADOTTI, 2003, p. 6I)

No mundo de hoje cada vez mais percebemos mudanças bruscas rapidamente, novas tecnologias, estudos e modos de aprender diferentes. Assim não devemos pensar no ensino como uma linha reta que não se modifica, na verdade é o contrário, os professores devem aprender diversas formas de ensinar, pois para se aprender com emoção é importante que os alunos gostem da forma que estão aprendendo. Aulas diferentes são importante para que não exista defasagem na educação. Devemos pensar sobre: "Só aprendemos quando colocamos emoção no que aprendemos. Por isso é necessário ensinar com alegria" (GADOTTI, 2003, p. 49).

O aluno triste não aprende; o aluno que tem fome não entende o conteúdo; o aluno triste não se interessa na educação. Emoções são importantes, o contexto diz muito sobre o processo de ensino. É imprescindível que a escola comece a levar mais em conta o lado pessoal da turma, não somente o dar aulas. Não somos robôs, nem maquinas, temos que ter um ensino personalizado e humanizado.

É importante consideram os fatores psicológicos das pessoas no meio da educação, pois causam mudanças positivas ou negativas no âmbito do ensino. Refletir sobre essas causas é investir num ensino de qualidade.

Os estudos sobre a aprendizagem devem considerar os fundamentos psicológicos $\mathrm{da}$ Pedagogia, os quais fornecem importantes respostas relacionadas às diferentes formas de relações entre os sujeitos (cognoscentes) e os objetos (cognoscíveis) de conhecimento, contemplando as etapas de desenvolvimento histórico e cultural porque passam esses mesmos sujeitos. (SEBRIAN, 2009,p. 09)

Segundo Gadotti (2003) os professores não têm muitas perspectivas nos empregos, são uma vaga a ser preenchida, mas e os educadores realmente estão satisfeitos? Quer dizer os sonhos e metas do professor normalmente veem em último lugar. Está cada vez mais difícil se manter na profissão com tanto desinteresse e desrespeito que os professores veem nas escolas. Muitos educadores estão insatisfeitos com seus trabalhos. O aluno por sua vez, 
não sabe muito bem o sentido de estar em estudando. De certa forma o ensino é desanimador de várias formas.

Como um professor enfrenta seus problemas em sala de aula; como ensinar com alegria em certos momentos; como aprender com emoção se os alunos estão desinteressados; qual a formula de ensino... são perguntas que nos deixam sem saber o que falar. É como se todos estivessem segurando a corda, quando um solta prejudica o outro.

A escola deve se preparar para as mudanças que ocorrem na sociedade, como: as novas tecnologias; a televisão; a internet; entre outros. São várias as formas que o aluno ocupa seu tempo fora da escola e isso implica e muito na fora que os alunos se comportam e reagem a inúmeras situações. Cada vez mais vemos crianças que praticamente nascem com celulares nas mãos, a TV é ainda mais invasiva chegando ao mundo infantil com poucos meses de vida, isso pode influenciar na educação das crianças, elas interagem mais com os meios de entretenimento do que com os pais.

\begin{abstract}
A escola precisa estar atenta às mudanças profundas que o contexto midiático contemporâneo está provocando na cabeça de crianças e jovens. Em média, no mundo, uma criança passa quatro horas diárias em frente à televisão. No Brasil, são oito horas. Em média, no mundo, a criança passa oito horas diárias na escola. No Brasil, são 4 horas. E mais: os professores passam mais tempo com as crianças do que os pais. Passamos muito tempo na escola, passamos muito tempo diante da televisão. (GADOTTI, 2003, p. 64).
\end{abstract}

É perceptível que são vários os problemas que os professores passam na prática docente, as dúvidas são muitas, sendo elas dos professores, alunos, orientadores, etc. Os professores da atualidade devem começar a pensar no 'ensinar os alunos a pensarem', a colaboração de todos na educação é o que nos dará êxito no ensino. O professor é um transformador de vidas e pessoas, toda mudança pode vir deles, as dificuldades são bem menores que as possibilidades existentes nessa profissão, a escola acolhe as crianças desde pequenas e só saem dela quase na vida adulta, o tempo que todos passamos na escola com os professores grande, quantas mudanças nos alunos podem ser feitas.

A esperança, para o professor, a professora, não é algo vazio, de quem "espera"
acontecer. Ao contrário, a esperança para o professor encontra sentido na sua
própria profissão, a de transformar pessoas, a de construir pessoas, e alimentar,
por sua vez, a esperança delas para que consigam, por sua vez, construir uma
realidade diferente, "mais humana, menos feia, menos malvada", como 
costumava dizer Paulo Freire. Uma educação sem esperança não é educação. (GADOTTI, 2003, p. 106).

Convém frisar que, o bom professor nunca para de aprender, e mostra os caminhos para que os alunos nunca parem de buscar conhecimento, ensina os alunos a aprenderem, modifica as formas de ensinar para que os alunos entendam o conteúdo. O professor hoje em dia, deve ter várias habilidades, mas claro, o professor não é um super-herói, devemos estar atentos no conjunto geral da educação.

Depois de várias analises, podemos afirmar, que a educação de sucesso começa pela união de saber ensinar como aprender, de estar por dentro do contexto dos alunos, e de aprender com emoção e ensinar com alegria, quando colocamos sentimentos e emoções no que fazemos fica muito mais fácil ter bons resultados. O professor deve descobrir o sentido de o porquê ensinar e mostrar para os alunos o sentido de porquê aprender. processo ensino-aprendizagem deve ter sentido para o projeto de vida de ambos, para que seja um processo verdadeiramente educativo" (GADOTTI, 2003, p. 68).

Estamos vivendo em uma pandemia onde muitas pessoas principalmente na educação já estão cansadas, alunos não aprendendo direito, professores com dificuldade de ensinar. Isso serve de lição para vermos a importância do ensino correto, percebesse que o profissional da educação cada vez mais tem que ter habilidades que ajudam a motivar os alunos. "profissional da educação é também um profissional que domina a arte de reencantar, de despertar nas pessoas a capacidade de engajar-se e mudar.” (GADOTTI, 2003, p. 71).

O caminho para o aprender e ensinar melhor, certamente está no ensino mais humanizado, que leve em conta as emoções, os quereres, os gostos, as diferenças... existem um mundo por trás de cada pessoa, cada aluno, cada professor. Temos que considerar pensar e repensar no ensino, entender que as emoções são aliadas ao ensino, aprender e reaprender a aprender, não só ensinar mas ensinar com alegria, ensinar para um mundo melhor. Vemos que existem realidades diferentes e que cada sala de aula existe suas peculiaridades, não é fácil mas pode ser possível. 


\section{FORMATAÇÃO DE ILUSTRAÇÃO}

As imagens escolhidas nos trazem a representação sobre o ensino com emoções e as aulas pós pandemia. Foi muito citado nos tópicos anteriores sobre a importância de colocar emoção em sala de aula. Podemos ver também a problemática de como vai ser retomada as aulas presenciais, já a mais de um ano em pandemia vamos perceber mudanças no comportamento de todos. A utilização de imagens faz com que fique visível alguns pontos que foram citados no texto, vemos o espelho de como funciona na prática.

A figura I representa o aprender com alegria, ensinar os alunos da melhor forma faz com que o professor se sinta realizado em dar aulas. $O$ bom convívio em sala de aula é imprescindível para a melhoria da educação, o país que tem uma educação de qualidade colhe bons frutos.

Figura I Aprender com alegria.

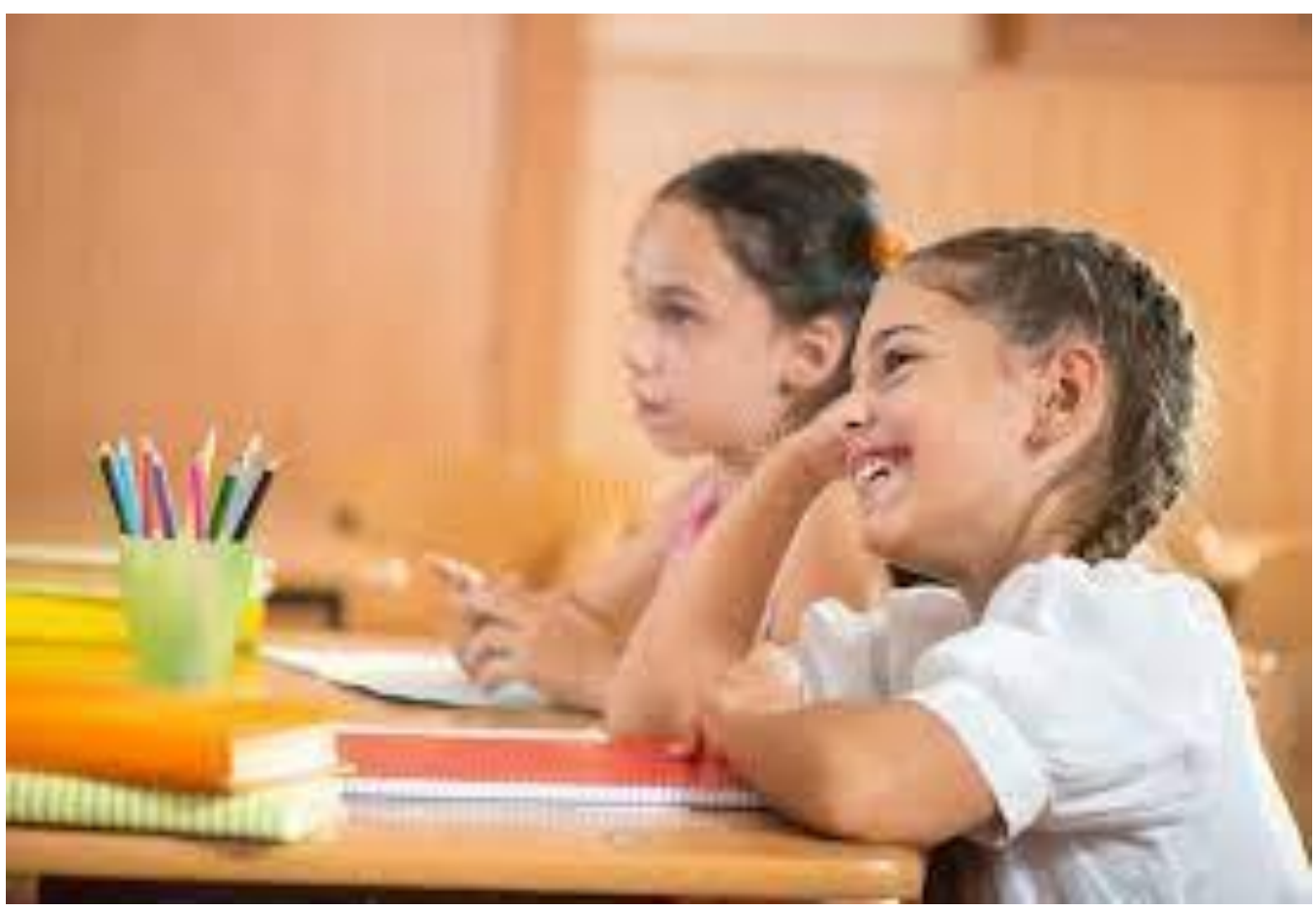

Fonte: https://pt.dreamstime.com/imagens-de-stock-alunos-felizes-na-escola-image37565244 Acesso Junho. 202I. 
A figura 2 mostra o cenário que vamos ter com a volta as aulas, na maioria das escolas do Brasil o ano letivo começou como reminou no ano passado (2020), com alunos em casa tendo aulas remotas. Ainda temos muito a se adequar com o ensino a distância, podemos ver que tanto os pais como os alunos e professores estão insatisfeitos com o ensino, já que, as crianças não aprendem da forma correta, vemos muitos problemas ainda no ensino remoto. No momento de retomada das aulas vamos ter que ter todos cuidados possíveis, pois a pandemia vai demorar para deixar de existir.

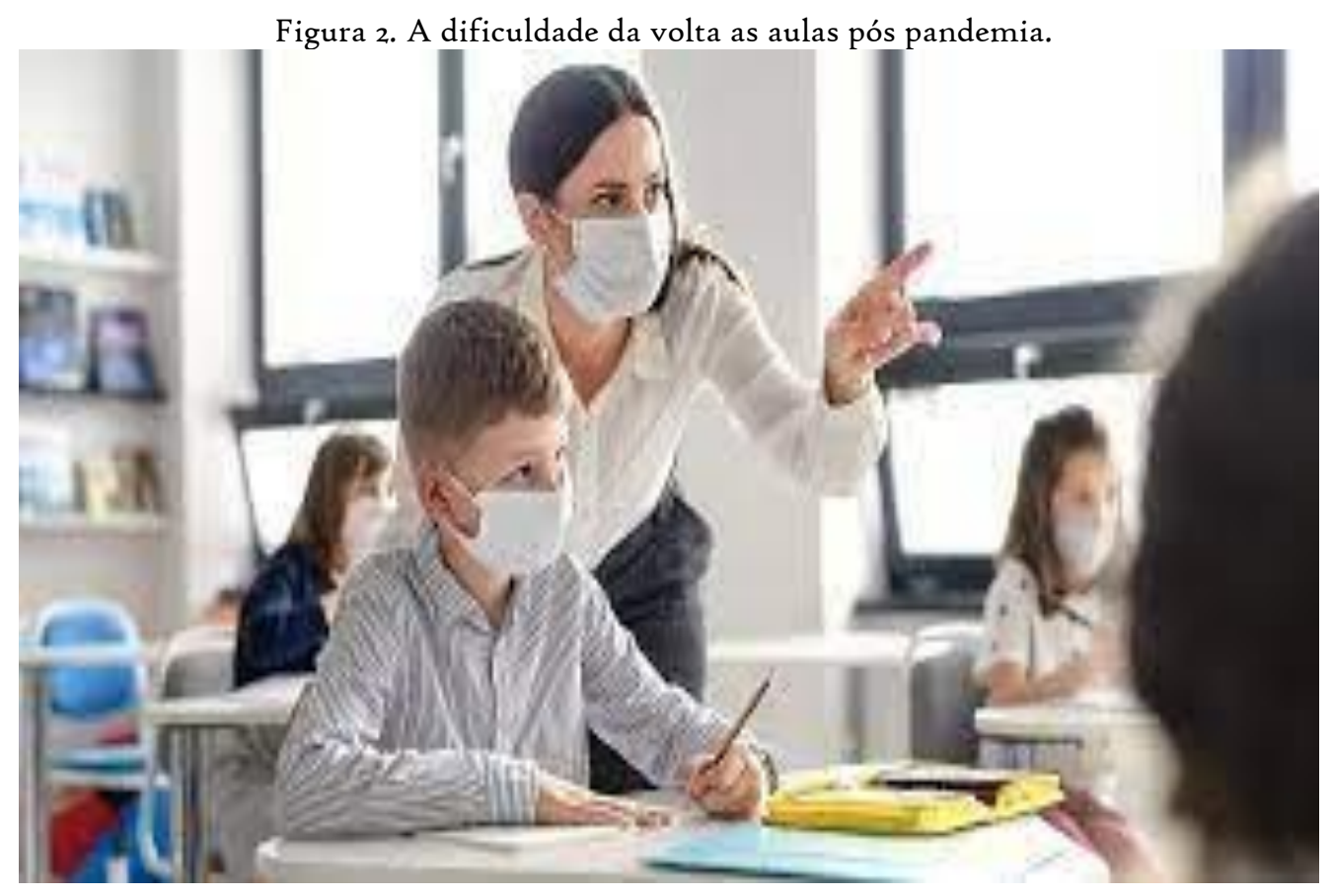

Fonte: https://escoladainteligencia.com.br/blog/volta-as-aulas-pos-pandemia/ Acesso Junho. 202I

\section{RESULTADOS DISCUSSÃO}

Sobretudo podemos fazer ligação da teoria com a prática dos conteúdos falados nesse artigo. As teorias estudadas contribuem com a prática do ensino, no momento que os professores têm dificuldades na sala de aula e começam a repensar as emoções e o contexto dos alunos, ensinar exige muito, aprender exige muito também, para não se tornar um trabalho cansativo e desmotivado tem que ser leve. Podemos ver em nossas rotinas isso. Um exemplo de como as emoções podem destruir o ensino é a 
pandemia em que viemos no momento, a maior parte das pessoas não estão satisfeitas, sendo assim acaba afetando negativamente na aprendizagem, pois digamos está um pouco pesada as coisas, pois muitos coisas ruins estão acontecendo. É perceptível que na prática tudo é mais difícil de fazer, porem os professores lutarem para um ensino humanizado dentro das escolas é importante, vejo que, quando um professor percebe o meio em que o aluno vive e leva em consideração as diferenças e contexto fica mais fácil ensina-lo.

\section{CONCLUSÃO}

Este trabalho oportunizou espaço de pesquisa sobre as vivências educativas qualificadas a partir de um processo integral de construção pedagógica, evidenciando-se questões pertinentes ao período de pandemia, contextualizando aos estudos de Gadotti (2003) sobre como é importante levar em conta as emoções, o aprendizado é importante, mas fica muito melhor quando o professor faz o ensino se tornar mais humano, quando percebe que aprender com emoção e ensinar com alegria é o que melhora o ensino nas escolas. O ensino não deve ser robotizado, mas sim, cada aula deve ser pensada levando em conta o contexto dos alunos. Porque essas situações são percebidas no contexto escolar.

Desta forma apontamos que a partir desta pesquisa tivemos como principais aprendizagens que: Aprendemos desde que nascemos e é a coisa mais importante que nos deixa vivo; que o professor deve analisar não só a sala de aula, mas o mundo em que o aluno vive; vemos que o professor pode melhorar o ensino se se sentir realizado e deixar o ensino mais leve e feliz, somos feitos de emoções; a pandemia deixou todos um pouco fragilizados; os educadores devem sempre estar atentos a mudanças sociais, sendo interessante que no percurso acadêmico novas perspectivas de pesquisa sejam eleitas a partir dessa empreitada, no que nos interessa, por exemplo, como exatamente ensinar com alegria; o quanto os alunos aprendem mais se estão com boas emoções e motivados; qual a nova forma de lidar com o ensino com as novas tecnologias; a pandemia prejudicou ou não o ensino e a aprendizagem. Existem várias questões por trás do aprendizado. 


\section{REFERÊNCIAS BILIOGRÁFICAS}

GADOTTI, Moacir. Boniteza de um sonho: Ensinar-e-aprender com sentido. Novo Hamburgo: Feevale, 2003.

SILVA, Adenilson e ORZECHOWSKI, Suzete. Psicologia e Educação: Fundamentos para a aprendizagem escolar. Guarapurava: Unicentro, 2009.

SILVA, Cássia M. M. Imagem x palavra: a recuperação da informação imagética. Interdiscursos da ciência da informação: arte, museu e imagem. Rio de Janeiro: IBICT/DEP, 2000. 